\title{
Interval Mapping of Quantitative Trait Loci for Corky Ringspot Disease Resistance in a Tetraploid Population of Potato (Solanum tuberosum subsp. tuberosum)
}

\author{
Dong-Man Khu • Jim Lorenzen • Christine A. Hackett • \\ Stephen L. Love
}

Published online: 5 September 2008

(C) Potato Association of America 2008 netic nature of CRS resistance was explained by major and minor QTLs association. Conversion of the three AFLP markers associated with this quantitative trait to simple PCR markers will benefit resistance breeding by enabling MAS.

Resumen La resistencia a la mancha de anillo corchoso (CRS) es un carácter ideal para el mejoramiento mediante la selección asistida por marcador (MAS), debido a la gran variabilidad de la incidencia de la enfermedad en el campo, la misma que complica el tamizado para resistencia. Para desarrollar marcadores moleculares asociados con resistencia a CRS, se construyó un mapa de ligamiento para una población tetraploide de 92 genotipos, con el fin de realizar un análisis de locus de un carácter cuantitativo (QTL). La población fue probada para resistencia a CRS tamizando por cuatro años en un campo infestado. La heredabilidad en sentido amplio de la resistencia a CRS, y su error estándar, fue de $0.80( \pm 16)$. Un total de 892 marcadores AFLP, 95 SSR y 5 SSCP fueron tomados en cuenta y usados para probar la asociación marcador-carácter. Un QTL mayor que explicó el 43\% de variación fenotípica en resistencia al CRS fue localizado en el cromosoma IX, con marcadores AFLP flanqueantes, AACCGT-0347 y ACG-CTG-0588. Un QTL menor que explicó el $12 \%$ de resistencia al CRS fue detectado también. Este QTL menor fue asociado con el marcador distorsionado CGT-CAC0259, el cual permaneció sin ligamiento. La naturaleza poligenética de la resistencia al CRS fue explicado por la asociación de los QTLs mayor y menor. La conversión de los tres marcadores AFLP asociados con este carácter cuantitativo en marcadores simples PCR, beneficiará el mejoramiento para resistencia haciendo posible la aplicación de MAS.

The Resumen was inadvertently omitted from this article which was published in vol. 85 no. 2, p. 129. It is reproduced here along with the English abstract.

Springer regrets the error.
S. L. Love $(\square)$

Aberdeen $\mathrm{R}$ and $\mathrm{E}$ Center, University of Idaho,

Aberdeen, ID 83210, USA

e-mail: slove@uidaho.edu 